\title{
Integration of remote sensing and bioclimatic data for prediction of invasive species distribution in data-poor regions: a review on challenges and opportunities
}

\author{
Nurhussen Ahmed ${ }^{1 *}\left(\mathbb{D}\right.$, Clement Atzberger $^{2}$ and Worku Zewdie ${ }^{1}$
}

\begin{abstract}
Prediction and modeling using integrated datasets and expertise from various disciplines greatly improve the management of invasive species. So far several attempts have been made to predict, handle, and mitigate invasive alien species impacts using specific efforts from various disciplines. Yet, the most persuasive approach is to better control its invasion and subsequent expansion by making use of cross-disciplinary knowledge and principles. However, the information in this regard is limited and experts from several disciplines have sometimes difficulties understanding well each other. In this respect, the focus of this review was to overview challenges and opportunities in integrating bioclimatic, remote sensing variables, and species distribution models (SDM) for predicting invasive species in data-poor regions. Google Scholar search engine was used to collect relevant papers, published between 2005-2020 (15 years), using keywords such as SDM, remote sensing of invasive species, and contribution of remote sensing in SDM, bioclimatic variables, invasive species distribution in data-poor regions, and invasive species distribution in Ethiopia. Information on the sole contribution of remote sensing and bioclimatic datasets for SDM, major challenges, and opportunities for integration of both datasets are systematically collected, analyzed, and discussed in table and figure formats. Several major challenges such as quality of remotely sensed data and its poor interpretation, inappropriate methods, poor selection of variables, and models were identified. Besides, the availability of Earth Observation (EO) data with high spatial and temporal resolution and their capacity to cover large and inaccessible areas at a reasonable cost, as well as progress in remote sensing data integration techniques and analysis are among the opportunities. Also, the impacts of important sensor characteristics such as spatial and temporal resolution are crucial for future research prospects. Similarly important are studies analyzing the impacts of interannual variability of vegetation and land use patterns on invasive SDM. Urgently needed are clearly defined working principles for the selection of variables and the most appropriate SDM.
\end{abstract}

Keywords: Bioclimatic variables, Remote sensing, Species distribution modeling, Invasive species

*Correspondence: nurhussenahmed40@gmail.com

${ }^{1}$ Department of Remote Sensing, Ethiopian Space Science and Technology Institute (ESSTI), Entoto Observatory and Research Center, Addis Ababa, Ethiopia

Full list of author information is available at the end of the article

\begin{abstract}
Introduction
Invasive species are a serious worldwide threat to biodiversity (Paz-Kagan et al. 2019; Somers and Asner 2012; Truong et al. 2017). They moreover negatively affect livelihoods (Shackleton et al. 2014, 2015), density, richness, and diversity of native woody species, and quality and distribution of water (Bekele et al. 2018). They have also a huge capacity to invade all land use types at high
\end{abstract}


invasion rates such as watercourses, highways, irrigated areas, forests, degraded lands, and agricultural land (Shiferaw et al. 2019c) in particular if the invaded areas have low diversity (Ilukor et al. 2016; Sun et al. 2015). The negative impact of invasive species is generally increasing over time as it usually requires huge amounts of labor and costs to eradicate infested areas (Bekele et al. 2018). In particular, relatively poor countries often don't have the necessary means to remove areas invaded by invasive species. Any deferment, however, further aggravates the problem (Vilà et al. 2011).

Currently, the adverse impacts of invasive species are in most countries by far greater than their positive return. In Ethiopia, the negative impact of Prosopis Juliflora (hereafter Prosopis) outweighs its positive contribution both to the ecosystem and livelihood (Iluker et al. 2014; Wakie et al. 2014). Currently, in Ethiopia, around 4.56 million hectares of land is highly suitable for Prosopis distribution (Sintayehu et al. 2020). In addition, in the Afar region, Prosopis has invaded about 1.17 million hectares of land and is expected to increase at a rate of 8.3\% annually (Shiferaw et al. 2019b). It invades native species and grasslands that were an important source of fodder for the locality (Ayanu et al. 2014; Wakie et al. 2014). Economically, an expected 535 billion dollars net loss may occur under poor management (Iluker et al. 2014). Hence, as eradication of invasive species is difficult and costly, early detection and prevention, using an integrated data source, need to be prioritized for its management (Paz-Kagan et al. 2019; West et al. 2014; Zimmermann et al. 2007). Although mapping current distribution and modeling of suitable habitat for invasive species are of particular interest, published reports are limited (Fischer et al. 2013; Ng et al. 2018).

Species distribution modeling (SDM) has a great potential for the identification of suitable habitats and modeling prediction of invasive species (Bradley 2014; Filho et al. 2010; Feilhauer et al. 2012; Truong et al. 2017). They are also useful for planning and management of conservation efforts involving at a range of different scales. They also help to address important policy and strategic concerns on a global scale (Cayuela et al. 2009). Even though invasive SDM makes field inventories more efficient and effective, their prediction potential is often limited by spatial bias, lack of spatially explicit predictor variables, and unavailability of species absence data (Cayuela et al. 2009; Filho et al. 2010; He et al. 2015). In view of this, the prediction of invasive species requires great care (Václavík and Meentemeyer 2012).

Advancements in remote sensing technology and statistical modeling increasingly support the prediction efficiency of SDM by reducing SDM-inherent limitations (He et al. 2015). Remotely sensed rainfall and temperature data are available at the different temporal and spatial resolutions but are not yet widely used (Amiri et al. 2020; Deblauwe et al. 2016; Fernandez et al. 2013). Normalized Difference Vegetation Index (NDVI), Leaf Area Index (LAI), Enhanced Vegetation Index (EVI), and other EO derived data are still under-used in SDM though their potential is unquestionable (Feilhauer et al. 2012; He et al. 2015; Klerk and Buchanan 2017). This is particularly important for data-poor regions such as Ethiopia where weather stations are scarcely found (Deblauwe et al. 2016; Truong et al. 2017). Most studies in Ethiopia were carried out using survey data which is costly and time-consuming. Though the use of remote sensing data is at its infant stage, in recent years some few studies were carried out using remote sensing and bioclimatic variables (Ayanu et al. 2014; Shiferaw et al. 2019a; Wakie et al. 2014).

Besides the contributions of remotely sensed environmental variables, bioclimatic variables are equally important for predicting invasive species distribution (Amiri et al. 2020; Bradley et al. 2018; Deblauwe et al. 2016; Fernandez et al. 2013). Though it has the coarse resolution, climate variables alone have great potential to predict invasive species while the presence of remotely sensed environmental variables supports to provide spatial detail (Truong et al. 2017; Zimmermann et al. 2007). So far, several review articles have been published regarding SDM (e.g.; Kissling et al. 2018; Urbina-Cardona et al. 2019), and invasive species (e.g.; Bartz and Kowarik 2019; Kapitza et al. 2019; Shackleton et al. 2015; Vilà et al. 2011) and role of remote sensing in invasive SDM (e.g.; (Bradley 2014; He et al. 2015; Huang and Asner 2009; D. Rocchini et al. 2015a, b; Royimani et al. 2018; Transon et al. 2018)). For example, Thamaga and Dube (2018a, b) have provided an overview of remote sensing on water hyacinth. Similarly, Matongera et al. (2016) have reviewed the advancement and challenges of remote sensing in mapping and sensing Bracken fern invasive species. Bradley et al. 2014 also provides a detailed description of the spectral, textural, and phenological approach of remote detection of invasive plants. Some review papers also focused on the impacts of climate-based variables in invasive species distribution (e.g.; Tricarico 2016; Zhao et al. 2013). However, to the best of our knowledge, studies to highlight the integration of different disciplines for accurate prediction of SDM are still missing. In light of this, Cord et al. (2013) wrote a commentary on the need for bridging disciplinary perspective for better use of their full potential. As the integration of remotely sensed environmental data sources, bioclimatic variables and SDM could be an effective and reliable tool to predict and map invasive species distribution; this review paper provides a review of the state-of-the-art in this field. 


\section{Methods}

The Google Scholar search engine was used to identify relevant papers. The following keywords/phrases were used alone and in combination to search published articles in the past 15 years:

- SDM

- Remote sensing of invasive species

- Contribution of remote sensing in SDM

- Bioclimatic variables

- Invasive species distribution in data-poor regions

- Invasive species distribution in Ethiopia

In this way, 442 papers were retrieved, published between 2000-2020. Out of these papers, 112 studies, published between 2005-2020 (March), were finally selected (Fig. 1). The main aim of the review was to describe challenges and opportunities in combining (bio) climatic (both in situ and/or remote sensing based) and EO derived variables with SDM for predicting invasive species distribution. In particular, the role of EO in the prediction of invasive species was thoroughly examined. Varied views of integrating these datasets with SDM were also explored. Major challenges and opportunities associated with the process of integrating these datasets were highlighted. Finally, recommendations were distilled out of the body of published work, providing some guidance concerning the design of future studies. To prepare this review paper, we first define the methodology used to select and analyze published (SCI) papers. Thereafter, in two separate chapters, we summarize the sole use of either (bio) climatic or EO data for SDM. The next chapter follows a summary of the combined use of the two datasets for SDM, followed by a review chapter on the use of such data for invasive species modeling in Ethiopia. Finally, we highlight the challenges and opportunities offered by a combined analysis of EO and (bio) climatic data. The review concludes with chapters on recommendations and conclusions.

\section{Results and discussion}

\section{Contribution of remote sensing in SDM}

Remote sensing is the most cost-effective approach to monitor vegetation cover and its changes over time, as it provides wide spatial coverage and repeated measurements over a short period, which are difficult to achieve otherwise (Paz-Kagan et al. 2019; Rocchini et al. 2015a, b; Rocchini et al. 2015a, b). The availability of

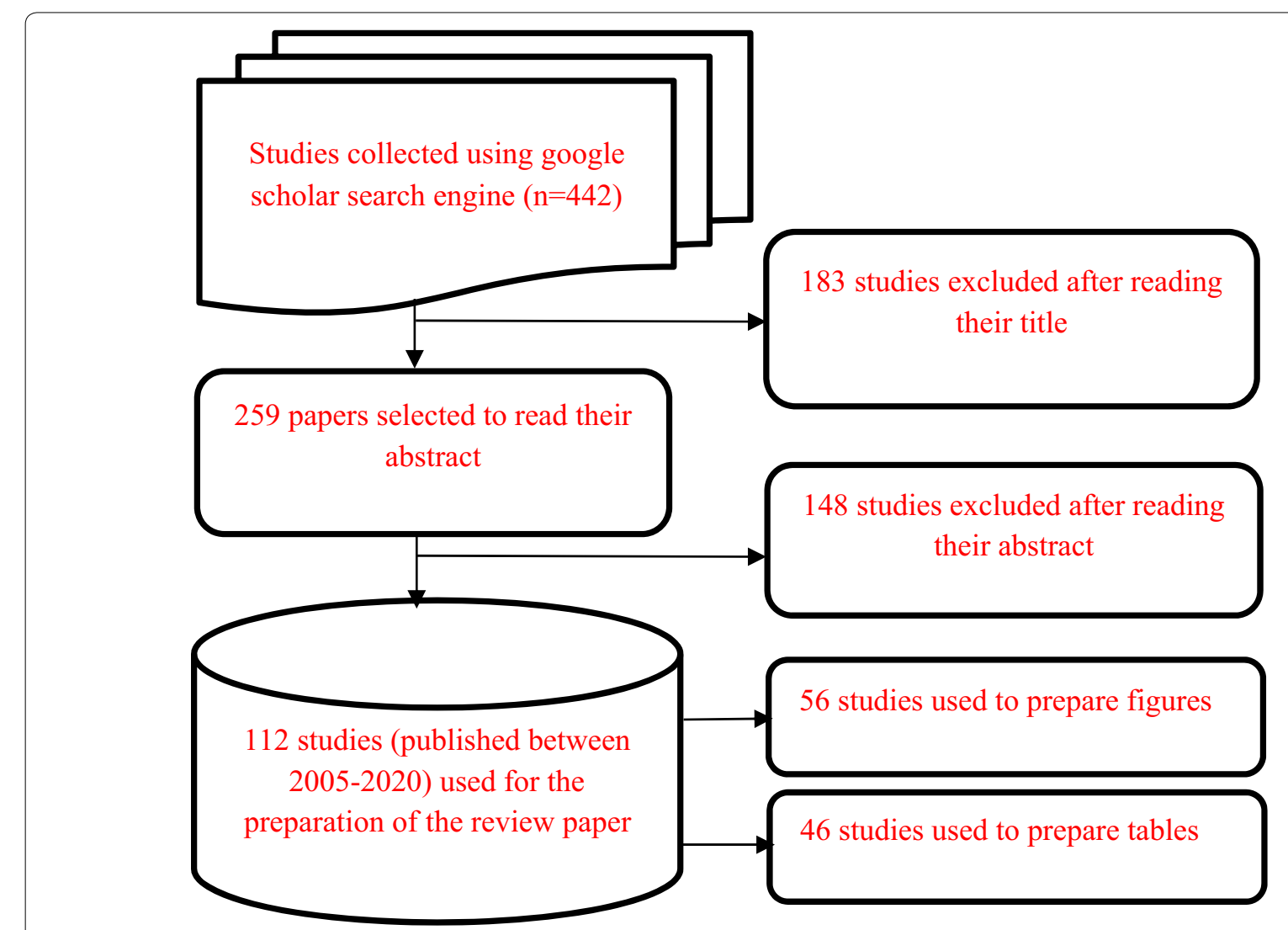

Fig. 1 Selection process of articles used for the review paper 
multi-temporal satellite data at varied spatial resolution has immense importance in modeling the distribution of invasive species (Bradley 2014; Buermann et al. 2008; Paz-Kagan et al. 2019; Saatchi et al. 2008; Truong et al. 2017). Several studies used multi-temporal and high spatial resolution data for mapping and modeling of invasive species (Evangelista et al. 2008; Huang and Asner 2009; $\mathrm{Ng}$ et al. 2017; Shiferaw et al. 2019a; Somers and Asner, 2012; Wakie et al. 2014).

Importantly, ongoing developments in remote sensing technologies lead to steadily improved sensors that have the potential to better support predictions of invasive species (Buermann et al. 2008; Huang and Asner 2009; Leitão and Santos 2019; Truong et al. 2017). With the availability of freely available Copernicus satellites (in particular Sentinel-2), unprecedented detail is offered every 5 days at the equator, for the identification of invasive species, (Ng et al. 2017; Rajah et al. 2018, 2019; Thamaga and Dube 2018a, 2018b) as well as crop and vegetation mapping (Immitzer et al. 2019; Shoko and Mutanga 2017; Vuolo et al. 2018; Wessel et al. 2018). The tremendous additional potential is offered by a steadily growing fleet of commercial satellites, UAV, and hyperspectral sensors (Feilhauer et al. 2013; Piiroinen et al. 2018).

Spectral characteristics of remotely sensed images permit to identify invasive species from native ones (Asner et al. 2008; Bradley 2014; Ouyang et al. 2013; Singh et al. 2013; Somers and Asner 2012). This is possible as EO data capture distinct spectral features stemming from (subtle) spectral characteristics of leaves and canopies of Morella faya and Psidium cattleianum (Asner et al. 2008; Somers and Asner 2012), Lantana camara L. (Oumar 2016), and Pteridium aquilinum L. (Singh et al. 2013), Spartina alterniflora (Ouyang et al. 2013), and Centaurea solstitialis L. (Ge et al. 2006).

As an example, Fig. 2, presents the spectral characteristics of invasive (I), nitrogen-fixing invasive (IN), native $(\mathrm{H})$, and nitrogen-fixing native $(\mathrm{HN})$ species in Hawaii in varied seasons. It shows that invasive species have (I) higher reflectance than native species $(\mathrm{H})$.

The provision of inter-annual satellite data offers additional profound advantages for the separation of individual species in different phenological cycles (Asner et al.
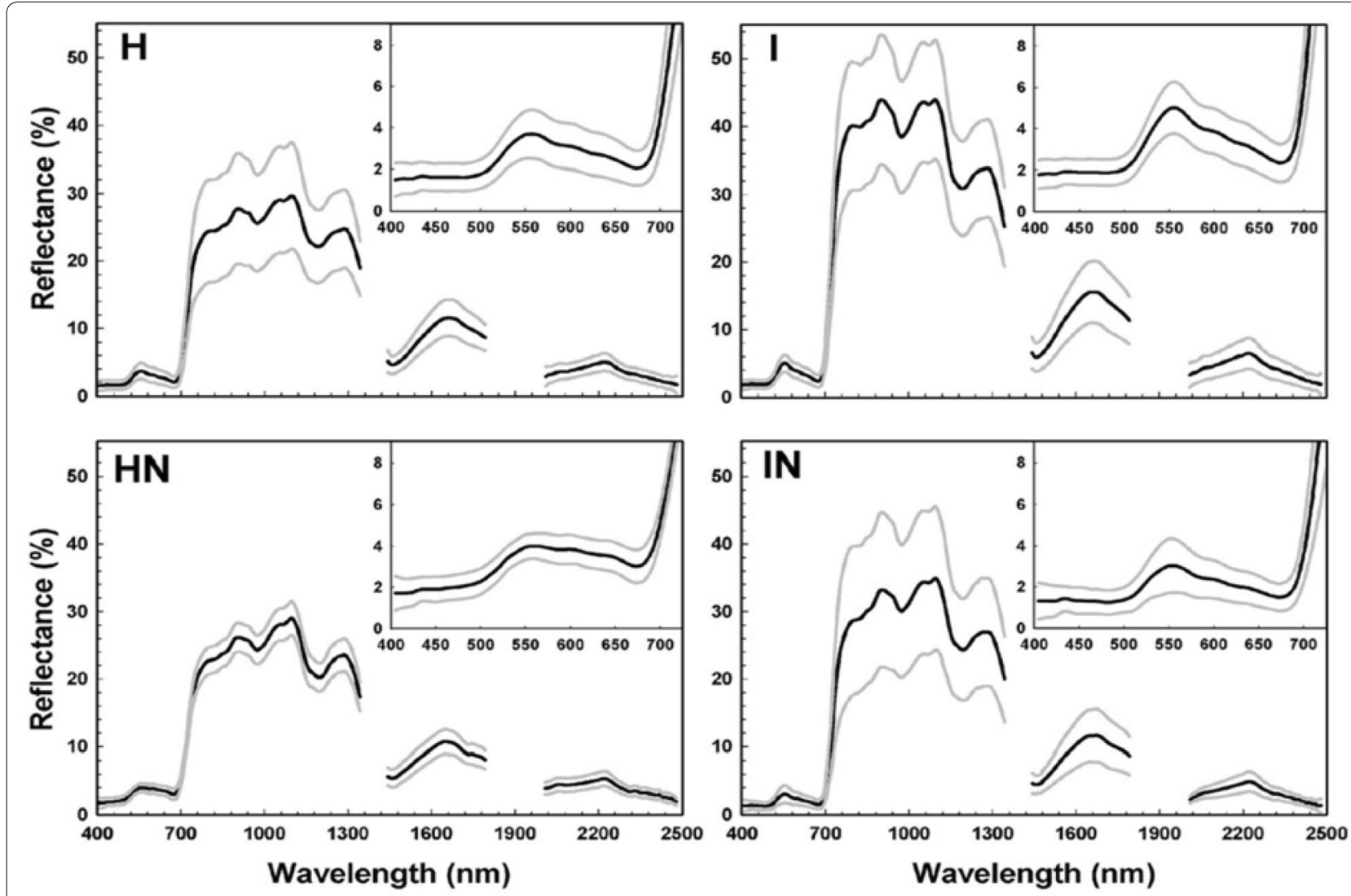

Fig. 2 Mean ( \pm S.D.) spectral reflectance of Invasive (I), native Hawaiian non-nitrogen-fixer (H), and native nitrogen-fixer (HN), and invasive nitrogen fixer (IN) species (Asner et al. 2008). It clearly describes the spectral separability of invasive and native species and the role of remote sensing in its identification is very high 
2008; Bradley 2014; Ge et al. 2006; Somers and Asner 2012). By observing the same target (pixel) multiple times during a growing cycle, additional (multi-temporal) indicators and features can be extracted, further benefiting the species identification. Understory invasive species that have a longer growing season in the early spring and late fall seasons for example can be identified from other trees using remote sensing (Bradley 2014).

Furthermore, EO data has a great potential to quantify environmental properties, biodiversity conservation, and detecting long-term change of ecosystem, often impossible to quantify otherwise (Cord et al. 2013; Prates-Clark et al. 2008; Taddese 2014). Moreover, the availability of multi-temporal remote sensing data permits ecologists to design SDM beyond climatic variables, by adding remotely sensed environmental variables (Cord and Rodder 2011). It has been pointed out that, incorporating remotely sensed environmental variables increases the acceptance of SDM for the prediction of invasive species (Leitão and Santos 2019). Climate and weather variables can also be derived from EO sensors and used for the prediction of invasive SDM, though published reports using this kind of application are limited (Deblauwe et al. 2016; Fernandez et al. 2013; Truong et al. 2017). Generally, the application of remote sensing products and their integration with climate data can create a better understanding of the field of SDM (Cord et al. 2013; Truong et al. 2017).

\section{Contribution of bioclimatic data in SDM}

For the better prediction of invasive species using SDM, it is necessary to include climate variables. Climate variables are one of the major contributing factors for predicting invasive species (Deblauwe et al. 2016; Fernandez et al. 2013; Re et al. 2020). SDMs perform better when climate data are used (either partially or completely) for model predictions (Ahmadi et al. 2020; Guisan et al. 2007; Truong et al. 2017; Zimmermann et al. 2007). Projection of invasive species distribution can also be possible using climate models (Heshmati et al. 2019). Unlike remote sensing, which mainly leverages the spectral signature of vegetation, climate data can provide information about environmental factors affecting species. Biophysical properties of vegetation can provide basic information on vegetation (Amiri et al. 2020; Deblauwe et al. 2016). For example, invasive species (Acacia melanoxylon R., Gleditsia triacanthos L.) often spread more widely in the dry season due to their unique biophysical characteristics to cope with water limitations (Godoy et al. 2011). Overlooking this will create inconsistencies in the prediction of invasive species distributions (Amiri et al. 2020; Bellard et al. 2018; Truong et al. 2017).
There are different sources of climate data sets that can be used for predicting invasive species. These data sources are either spatially interpolated (e.g.; WorldClim, Climatic Research Unit (CRU)), or satellite-based estimates of climatic variables (e.g.; Tropical Rainfall Measuring Mission (TRMM) and Moderate Resolution Imaging Spectrometer (MODIS). For example, in WorldClim, climate data is spatially interpolated using spline interpolation. This data is very popular to use for invasive SDM (Hijmans et al. 2005; Vega et al. 2017). However, there are some uncertainties in this product as it can be affected by closeness to weather stations, inter-annual variability, and topographic heterogeneity (Amiri et al. 2020; Fernandez et al. 2013). As a result, WorldClim as well as other station-based climate data is always uncertain for the prediction of invasive species distribution when ground weather stations are sparse (Amiri et al. 2020; Deblauwe et al. 2016). In such cases, the inclusion of satellite-based climate data improves the prediction of invasive species compared to models that only consider spatially interpolated climate data (Engler et al. 2013). Figure 3 describes a methodological flow chart on how to derivate bioclimatic variables from remotely sensed datasets. Even if remotely sensed climate data has great potential in providing better temporal and spatial resolution, the EO should always be examined and validated using station based climate data to check their accuracy (Loew et al. 2017; Richter and Hank 2012).

\section{Integration of remote sensing and bioclimatic variables}

Invasive SDM can benefit from using bioclimatic, survey, remote sensing data, and/or integration of all with SDM. Predicting the risk of invasive species at different scales can be quantified by readily available remote sensing products in conjunction with climate data and SDM (Wakie et al. 2014; Zimmermann et al. 2007). However, there is no consensus among scientists whether the integration of both datasets with SDM can enhance the prediction of species distribution or not. Some researchers argue that integration of both datasets with SDM has huge potential for efficient mapping of species distribution, compared to using remotely sensed or climate data alone (Arogoundade et al. 2019; Buermann et al. 2008; Prates-Clark et al. 2008). Other papers revealed that the integration of both datasets could even decrease the accuracy of modeling due to the quality of remotely sensed environmental variables (land cover) (Engler et al. 2013; Truong et al. 2017; Zimmermann et al. 2007).

In addition, a study by Truong et al. (2017), evaluated the performance of bioclimatic and remote sensing data separately and in combination using the MaxEnt model. They concluded that despite the challenges, the integration of both datasets had a promising future for 


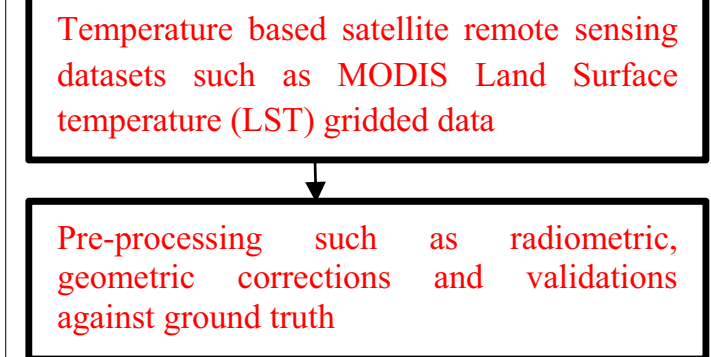

Derivation of temperature based bioclimatic variables such as annual mean temperature $\left({ }^{\circ} \mathrm{C}\right)$, mean diurnal range $\left({ }^{\circ} \mathrm{C}\right)$. This can be done in different tools such as ArcGIS and R software's
Rainfall based satellite remote sensing datasets such as TRMM and CHIRPS gridded data

Pre-processing such as radiometric, geometric corrections and validations against ground truth

Derivation of rainfall based bioclimatic variables such as annual precipitation ( $\mathrm{mm})$, precipitation of wettest month ( $\mathrm{mm})$. This can be done in different tools such as ArcGIS and R software's

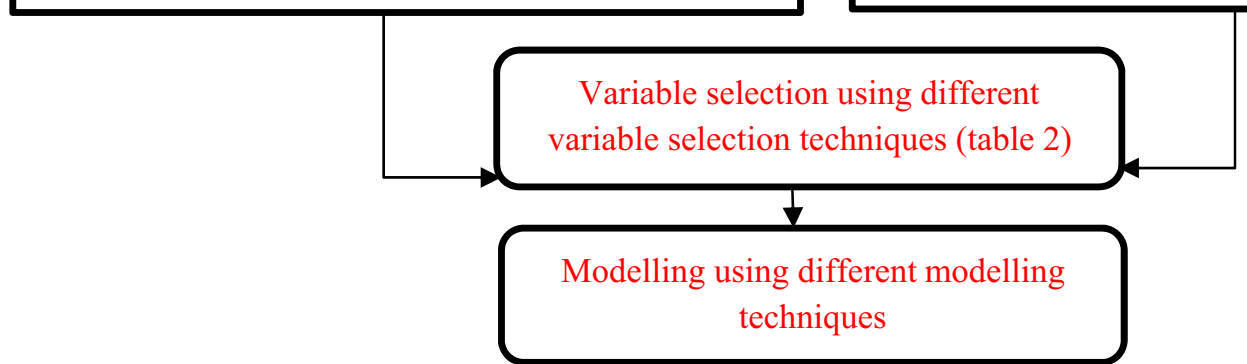

Fig. 3 Derivation of bioclimatic variables from remotely sensed data (adapted from Amiri et al. 2020; Deblauwe et al. 2016)

invasive SDM. Similarly, a study by Wakie et al. (2014), employed the MaxEnt model for integration of 19 bioclimatic variables with remotely sensed environmental parameters. Their study revealed that the integration of both datasets enhances the prediction of invasive species, particularly in areas where sufficient ground survey is difficult to undertake. Besides, a study by Feilhauer et al. (2012) combined 19 WorldClim bioclimatic data with MODIS NDVI time-series data to determine species distribution at coarse spatial resolution. They indicated that there is a strong improvement in species prediction when data are combined. However, completely ignoring EO variables and fully depending on climate data, or even excess of climate variables, might lead to unreliable results (Li et al. 2014). Hence, combining spatially interpolated ground stations with remotely sensed climate data has profound importance to accurately utilize their respective benefits sides while reducing their limitations. Besides, for an improved prediction of invasive species several requirements are of utmost importance:

- High spatial, temporal, and spectral resolution satellite products (Engler et al. 2013; Truong et al. 2017)

- Proper selection of environmental variables (Cord and Rodder 2011; Zimmermann et al. 2007), and
- Appropriate techniques to integrate both data sets (Cord et al. 2013; Guisan et al. 2007)

Several studies followed the below flowchart (Fig. 4) to integrate remote sensing and bio (climatic) variables for a particular species distribution modeling. The first requirement is to select remote sensing and bio (climatic) datasets. Once the datasets are selected the next step is to select the best-performed variables. After appropriate variables are selected the next step is to choose the modeling technique. Moreover, model performance can be computed using different approaches and bestperformed variables from both models can be selected for the integration of remote sensing with bio (climatic) based model. The overall process to integrate both datasets is presented in Fig. 4.

Furthermore, a few papers are summarized in Table 1 that focuses on the prediction of species using both datasets. This yields insights on the kind of variables and SDM was most often used in combining the two datasets for the prediction of invasive species.

From Table 1, the following observations are extracted:

- There is poor agreement on the process of selecting variables and SDM for the prediction of invasive species distribution. 


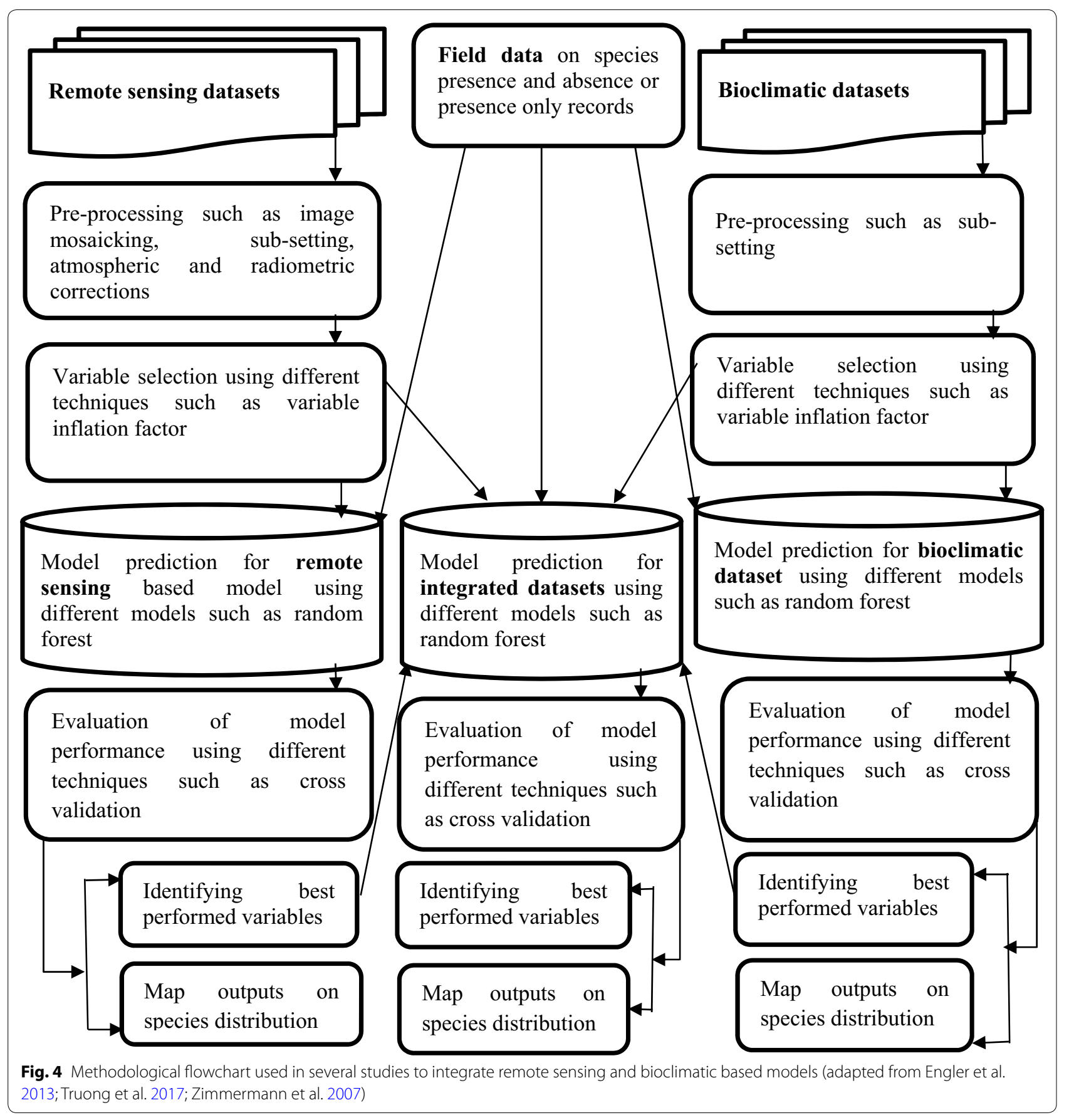

- Justifications to select (or ignore) variables and SDM are overlooked.

- Although integration of remotely sensed environmental variables, bioclimatic variables, and SDM are highly valuable for studying species distribution, methods that specifically work on the integration of $\mathrm{EO}$ and bioclimatic variables are requiring.

\section{Experiences in Ethiopia}

More than 35 invasive alien species are reported in Ethiopia (Shiferaw et al. 2018; Tamiru 2017). However, only a few attempts were made to map their distribution. For example, Prosopis (Ayanu et al. 2014; Hundessa and Fufa 2016; Shiferaw et al. 2019a; Wakie et al. 2014), Mimosa diplotricha (Wakjira 2011); Parthenium hysterophorus 
Table 1 Variables, SDM, and species used in combination of both datasets of some researches

\begin{tabular}{|c|c|c|}
\hline Variables & SDM & References \\
\hline $\begin{array}{l}\text { Climate variables (mean annual rainfall, mean monthly tem- } \\
\text { perature, monthly land surface temperature during day and } \\
\text { night time) } \\
\text { Remote sensing variables (monthly land surface temperature } \\
\text { during the day and nighttime, panchromatic reflectance, } \\
\text { red reflectance, near-infrared reflectance, shortwave } \\
\text { infrared band } 6 \text { reflectance, NDVl, elevation, slope, relief, } \\
\text { landform, rugged, and distance to River) } \\
\text { Survey data (distance to road, distance to village) }\end{array}$ & Random Forest (RF) & Shiferaw et al. (2019a) \\
\hline $\begin{array}{l}\text { Climate variables (temperature seasonality) } \\
\text { Remote sensing variables (elevation, landform, lithology, } \\
\text { distance to water, distance to urban areas) } \\
\text { Survey data (distance to road) }\end{array}$ & RF, MaxEnt, logistic regression, Bayesian networks, Ensemble & Ng et al. (2018) \\
\hline $\begin{array}{l}\text { Climate variables (19 WorldClim bioclimatic variables) } \\
\text { Remote sensing variables (bedrock, bulk density, cation } \\
\text { exchange capacity, soil texture fraction clay, coarse frag- } \\
\text { ments volumetric, soil organic carbon stock, soil organic } \\
\text { carbon content, soil pH, soil texture fraction silt, soil texture } \\
\text { fraction sand, land cover, gross primary productivity, coef- } \\
\text { ficient of variation, gross primary productivity, elevation) }\end{array}$ & MaxEnt & Truong et al. (2017) \\
\hline $\begin{array}{l}\text { Climate variables (WorldClim variables and MODIS land } \\
\text { surface temperature) } \\
\text { Remote sensing variables (long term EVI, surface reflectance } \\
\text { including blue, red, near-infrared, and middle infrared wave- } \\
\text { lengths and land cover data) }\end{array}$ & MaxEnt & Cord et al. $(2014 a, b)$ \\
\hline $\begin{array}{l}\text { Climate variables (WorldClim bioclimatic variables) } \\
\text { Remote sensing variables (monthly NDVI and EVI), elevation } \\
\text { and slope }\end{array}$ & MaxEnt & Wakie et al. (2014) \\
\hline $\begin{array}{l}\text { Climatic variables (growing degree days, mean temperature } \\
\text { of the coldest month, summer moisture index, summer } \\
\text { sum of precipitations, winter sum of precipitations, yearly } \\
\text { solar radiation, summer solar radiation, soil water balance, } \\
\text { topographic wetness index, topographic position } \\
\text { Remote sensing variables (NDVI, Renormalized Difference } \\
\text { Vegetation Index (RDVI), Modified Simple Ratio index (MSR), } \\
\text { Modified Chlorophyll Absorption Ratio Index } 1 \text { (MCARI1), } \\
\text { blue band, green band, red band, near-infrared band, slope } \\
\text { and topographic position, distance to the nearest water } \\
\text { body) }\end{array}$ & $\begin{array}{l}9 \text { SDM including Generalized Linear Model (GLM), RF, Artifi- } \\
\text { cial Neural Network, and Ensemble model }\end{array}$ & Engler et al. (2013) \\
\hline $\begin{array}{l}\text { Climatic variables (WorldClim bioclimatic variables) } \\
\text { Remote sensing variables (NDVI) }\end{array}$ & Partial Least Squares regression & Feilhauer et al. (2012) \\
\hline $\begin{array}{l}\text { Climatic variables (WorldClim bioclimatic variables) } \\
\text { Remote sensing variables (LAl, vegetation density, seasonality, } \\
\text { and net primary productivity, forest cover, and heteroge- } \\
\text { neity, surface moisture, and roughness (forest structure), } \\
\text { seasonality, topography, and ruggedness) }\end{array}$ & MaxEnt & Buermann et al. (2008) \\
\hline $\begin{array}{l}\text { Climatic variables (WorldClim bioclimatic variables) } \\
\text { Remote sensing variables (monthly NDVI, monthly LAI, percent } \\
\text { tree cover, scatter meter backscatter monthly composites at } \\
1 \text { km, elevation) }\end{array}$ & MaxEnt & Prates-Clark et al. (2008) \\
\hline $\begin{array}{l}\text { Climatic variables (Bioclimatic variables derived from DAYMET) } \\
\text { Remote sensing variables (NDVI) }\end{array}$ & GLM & Zimmermann et al. (2007) \\
\hline
\end{tabular}

L. (Beyene and Tessema 2015) are to mention most. Out of the papers retrieved for this review, 23 focused on the distribution of invasive species in Ethiopia. However, only seven of those studies employed satellite data or bioclimatic data and/or a combination of both datasets. The rest used survey data to map the distribution of invasive species, which is very difficult and time-consuming. For example, (Beyene and Tessema 2015; Hundessa and Fufa 2016; Tola and Tessema 2019; Wakjira 2011) followed the same methodology for various invasive species. These 
authors gathered survey data at $10 \mathrm{~km}$ intervals; ignoring remote sensing and bioclimatic variables.

In the Afar region Ayanu et al. (2014), employed long term satellite data to provide basic information on the historical distribution of Prosopis and land-use changes and conclude that the role of long term remote sensing data has great contribution to manage invasive Prosopis distribution. In addition, Shiferaw et al. (2019a) used long term satellite data to quantify Prosopis distribution and its impact on land-use changes and ecosystem services and conclude that remote sensing data has a great contribution to quantify land cover changes and ecosystem services. Similarly, Wakie et al. (2014) and Shiferaw et al. (2019a) took into account both bioclimatic and remotely sensed variables for prediction of invasive Prosopis using MaxEnt and RF models respectively, and conclude that the use of integrated datasets has great importance in studying invasive species distribution and prediction. Shiferaw et al. (2019a) provided a comparison study on the performance of SDM in the prediction of Prosopis and conclude that the use of the best-performing machine learning algorithm provides better accuracy than the ensemble model. Moreover, West et al. (2014) provided extensive information on the potential distribution of Prosopis in Ethiopia using the Landsat 8 and MaxEnt model (Fig. 5). Overall, remotely sensed satellite data and bioclimatic variables have been scarcely used for mapping invasive species distribution in Ethiopia, indicating that the use of these data is still in its infancy in the country.

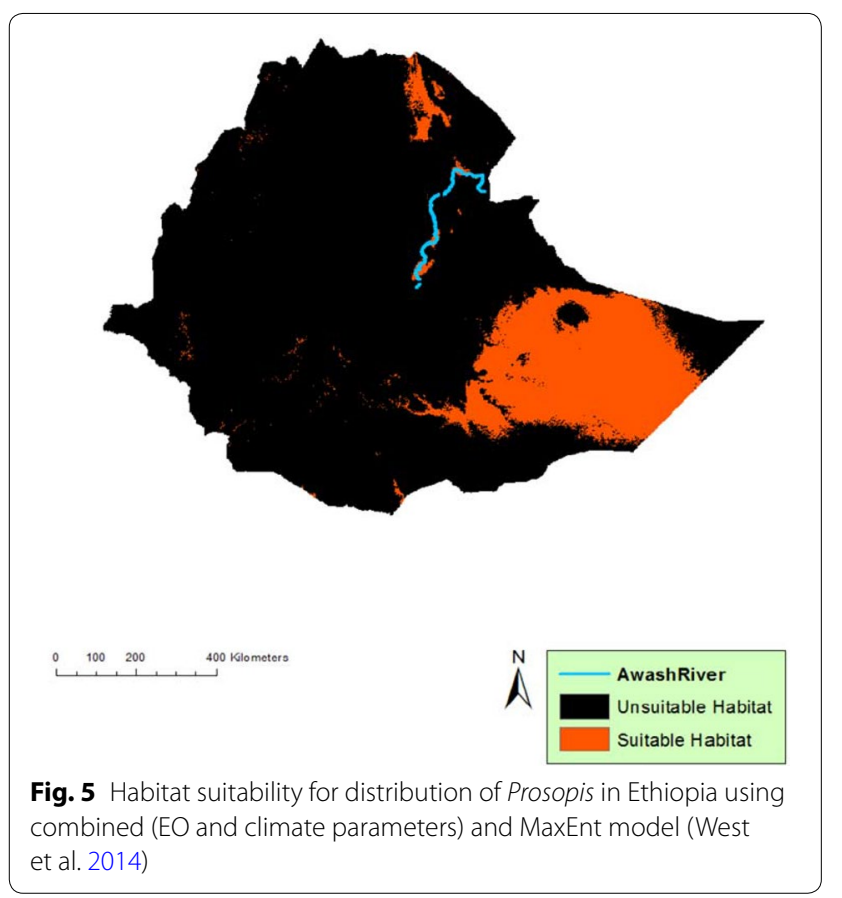

Challenges in the combination of EO and climate datasets Combining EO and climate data is not without challenges. Major problems relate to:

1. The nature of species (invasive species are more difficult than native ones) (Evangelista et al. 2008; Václavík and Meentemeyer 2012),

2. Poor methodology in the selection of variables (Guisan et al. 2007),

3. Inappropriate selection of models (Guisan et al. 2007),

4. Quality issues of the data (Cord and Rodder 2011; Truong et al. 2017; Tuanmu and Jetz 2014), and

5 . The difficulty of interpretation of remotely sensed data (Cord and Rodder 2011).

Unlike other species, mapping and modeling of invasive species require the highest care as it violates major assumptions known in SDM (Václavík and Meentemeyer 2012). Besides, remote sensing limitations such as failure to detect all plants, the trade-off between spatial with temporal and spatial with spectral resolutions negatively affects SDM application (He et al. 2015). It is also pointed out that, it is difficult to find reliable, high-quality land cover remotely sensed information at any time is also a great challenge (Bradley and Fleishman 2008; PratesClark et al. 2008). In addition to quality concern, the interpretation of remotely sensed signals is also challenging and disturbs the accuracy of other variables (Cord and Rodder 2011; Zimmermann et al. 2007).

Another major challenge relates to the fact that remote sensing toolset consists of sensors with widely varying sensor characteristics (Saatchi et al. 2008; Tuanmu and Jetz 2014). For example, the spatial resolution has a strong impact on the prediction of invasive species. The coarse spatial resolution of satellites limits certainly details of the map, whereas fine resolution brings its own problem in relation to cost, preprocessing, and intra-class variability (Boyd and Foody 2011).

Sample size and design in presence and absence data is also another challenge in SDM (Fithian et al. 2014; Rocchini et al. 2015a, b). Most researchers used the only presence or pseudo absence data for modeling prediction of species distribution as absence data for invasive species are difficult to obtain (Ng et al. 2018; Václavík and Meentemeyer 2012). In addition, employing a reasonable sample size using appropriate techniques can enhance the prediction of species distribution (Xie et al. 2008).

Proper selection of SDM can significantly increase the efficiency of prediction. Selecting a specific model needs to provide justifiable criteria as it can affect the result (Sakate and Kashid 2016). However, in most cases, models are selected without providing significant justification. 


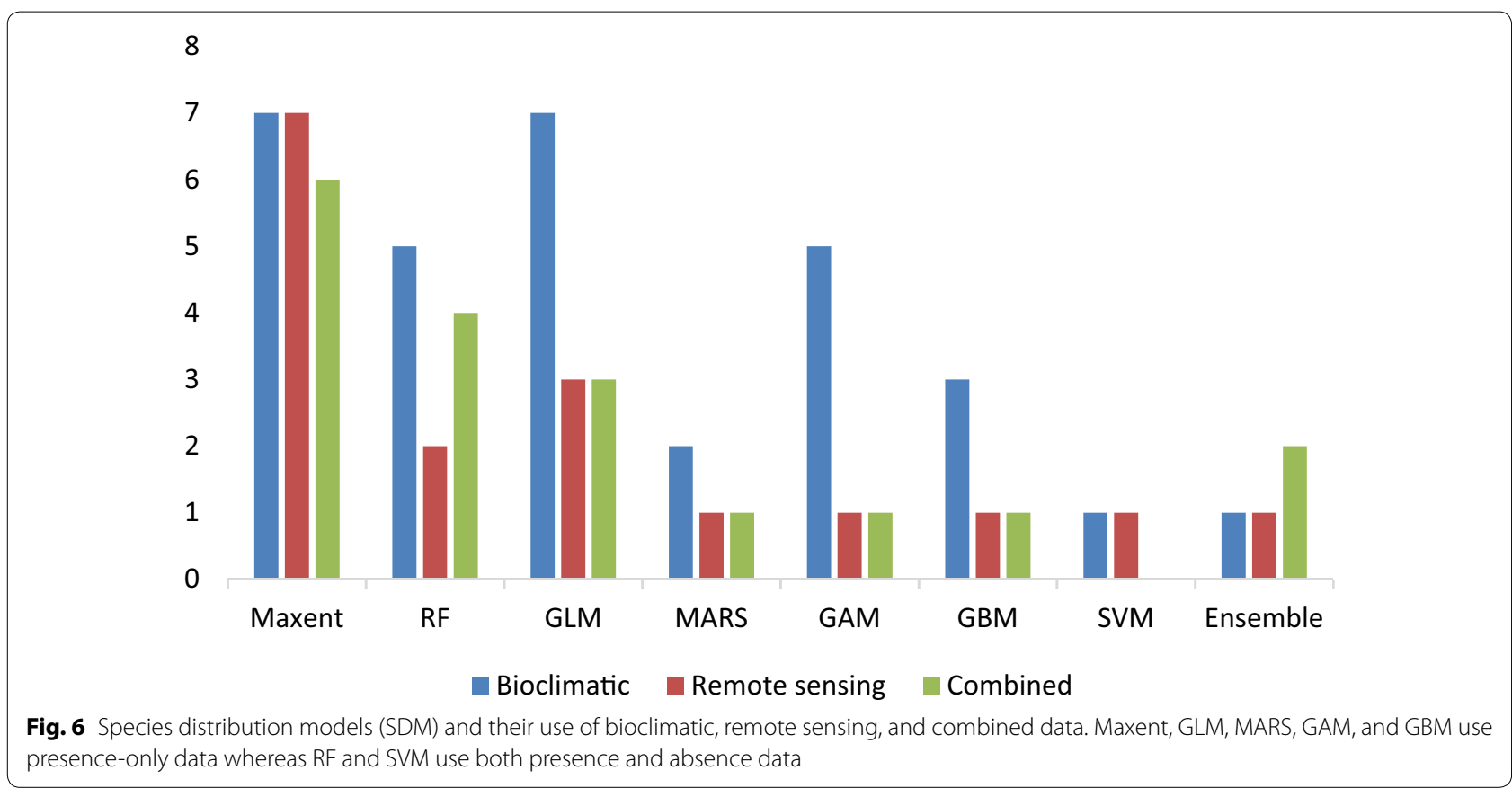

Table 2 Variable selection techniques used in the integration of remote sensing and bioclimatic based variables

\begin{tabular}{lll}
\hline S.no & Variable selection methods & References \\
\hline 1 & Correlation (Pearson, Kendall, Spearman) & Buermann et al. (2008); Engler et al. (2013); Gormley et al. (2011); Ng et al. \\
& & (2018); Saatchi et al. (2008); Truong et al. (2017); Wakie et al. (2014); West \\
et al. (2014); Zimmermann et al. (2007) \\
2 & Principal component analysis & Deblauwe et al. (2016); Feilhauer et al. 2012; Jensen et al. (2020) \\
3 & Variance inflation factor & Ahmadi et al. (2020); Ng et al. (2018); Shiferaw et al. (2019c) \\
5 & Weighted mean fitted analysis approach & Shiferaw et al. (2019a) \\
6 & Permutation importance & Wilson et al. (2013) \\
\hline
\end{tabular}

Some researchers use single models for mapping and predicting invasive species distribution (e.g.; MaxEnt model used by Truong et al. 2017; Wakie et al. 2014). Some other researchers first compare different models and then use the best performing model for prediction (e.g. Engler et al. 2013; Ng et al. 2018; Shiferaw et al. 2019a). Other papers suggest that ensemble models are preferable over single models (e.g.; Früh et al. 2018; Ng et al. 2018)). Figure 6 depicts various SDM employed bioclimatic data, remote sensing data, or their combination. Maximum entropy (MaxEnt), RF, GLM, Multivariate Adaptive Regression Splines (MARS), Generalized Additive Model (GAM), Gradient Boosted Model (GBM), ensemble model, and Support Vector Machine learning (SVM) are analyzed within about 49 studies.

As indicated in Fig. 5, GLM and MaxEnt are largely used in bioclimatic and remote sensing based research. This might be attributed to the challenge of collecting absence data for invasive species (Ng et al. 2018; Václavík and Meentemeyer 2012). MaxEnt is popular in SDM, through evaluating the quality of SDM is difficult (Filho et al. 2010; West et al. 2014). From the presence and absence of data models, the RF is the most employed model in bioclimatic, remote sensing, and integrated datasets.

\section{Variable selection methods}

To ensure a non-bias variable selection, it is important to determine variable correlation through a set of standardized tests (Phillips et al. 2006). It is hard to know; however, in which environmental variables are most appropriate and useful for predicting species distribution (Aranda and Lobo 2011). The importance of environmental variables is dependent on the type, nature of species, and its topography (Cord et al. 2013). Due to this, we can't see consistent variables used by researchers for 
Table 3 Variables and their data sources used for integrating (bio) climatic and remote sensing data

\begin{tabular}{|c|c|c|}
\hline Variables & Data sources & References \\
\hline Bioclimatic variables & WorldClim database & $\begin{array}{l}\text { Buermann et al. (2008); Cord et al. (2014a, b); Feilhauer et al. (2012); Ng et al. (2018); } \\
\text { Prates-Clark et al. (2008); Truong et al. (2017); Wakie et al. (2014) }\end{array}$ \\
\hline Long term NDVI & Landsat, MODIS, Airborne Digital Sensor & $\begin{array}{l}\text { Engler et al. (2013); Evangelista et al. (2008); Feilhauer et al. (2012); Ng et al. (2018); } \\
\text { Shiferaw et al. (2019a); Shiferaw et al. (2019c); Wakie et al. (2014) }\end{array}$ \\
\hline Long term EVI & MODIS & Cord et al. (2014a, b); Wakie et al (2014) \\
\hline LAl & MODIS & Buermann et al. (2008); Engler et al. (2013); Prates-Clark et al. (2008); Saatchi et al. (2008) \\
\hline Near-Infrared band & Landsat, Airborne Digital Sensor & Engler et al. (2013); Shiferaw et al. (2019a); Zimmermann et al. (2007) \\
\hline Land cover & Tuanmu and Jetz 2014 & Truong et al. (2017); Tuanmu and Jetz (2014) \\
\hline Vegetation density & Tuanmu and Jetz 2014 & Truong et al. (2017); Buermann et al. (2008) \\
\hline Elevation & SRTM, ASTER, GTOPO30 & $\begin{array}{l}\text { Bradley and Mustard (2006); Buermann et al. (2008); Ng et al. (2018); Prates-Clark et al. } \\
\text { (2008); Saatchi et al. (2008); Shiferaw et al. (2019a); Truong et al. (2017) }\end{array}$ \\
\hline Slope & SRTM, ASTER & Ng et al. (2018); Shiferaw et al. (2019a) \\
\hline Distance from road & Survey data & Ng et al. (2018); Shiferaw et al. (2019a) \\
\hline Distance from water & SRTM & Engler et al. (2013); Ng et al. (2018); Shiferaw et al. (2019a) \\
\hline Distance to Village & Landsat, Survey data & Ng et al. (2018); Shiferaw et al. (2019a) \\
\hline
\end{tabular}

the prediction of species distribution even with similar climate, species, and study locations. The selection of significant variables is a crucial step and can determine the accuracy of models (Beaumont et al. 2005; Elkind et al. 2019). The following are (Table 2) among the variable selection methods used in several studies.

Furthermore, the following variables were selected in many invasive species prediction studies using the above variable selection techniques.

From Table 3, bioclimatic variables, long-term NDVI, EVI, elevation, and slope are most widely used for the prediction of invasive species. Generally, challenges in integrating bioclimatic and remote sensing variables with SDM are the results of the overall problems listed above.

\section{Opportunities for combining climate and EO datasets}

Despite its challenges, integration of climate and EO data sets with SDM for invasive species has a promising future. The availability of fine resolution and multitemporal remote sensing data is a unique opportunity for SDM (Cord et al. 2014a, b). This is particularly the case as more and more EO data become freely available, and both data quality and information content increase through time (Saatchi et al. 2008).

The development of techniques to check and validated the accuracy of SDM is also an important research opportunity (Václavík and Meentemeyer 2012). Many SDM that support the adoption of remote sensing data for invasive species distribution are available. Ensemble SDM is considered as a major way forward in the field of SDM (Früh et al. 2018; Ng et al. 2018).

The application of Unmanned Aerial Vehicle (UAV) in SDM is a great asset as it provides fine resolution at minimum cost for species-level monitoring (Fritz et al. 2018), as long as the area of interest is relatively small $\left(<1 \mathrm{~km}^{2}\right)$. An image fusion technique that integrates different sensors to provide better temporal and spatial resolution is considered as a good forward for better prediction (Xie et al. 2008). Advancements in satellitebased (bio) climate data, and techniques to integrate with ground-based weather stations, are also considered useful for better prediction of invasive species (Amiri et al. 2020; Deblauwe et al. 2016; Fernandez et al. 2013) (Table 4).

\section{Recommendations}

Through advancements in remote sensing science, technology, application, and machine learning provide a better prediction of invasive species, more research in ecology and remote sensing experts is needed. This includes on one hand a better understanding of distribution patterns of invasive species and on the other hand an improved knowledge about the most important spectral bands and acquisition times to permit an effective and robust identification of the target species. There is moreover a strong need to develop basic working principles and procedures in the selection of environmental variables and SDM. Such a selection needs to consider the nature of species, SDM, and available datasets.

On the remote sensing side, detailed information can be obtained at high spatial and temporal resolution owing to the open access policy of most satellite data owners. Freely available Sentinel-2, Landsat, and MODIS data are particularly necessary for developing countries as the cost of high-resolution images are difficult to justify. The fusion of image data from multiple sensors will lead to an 


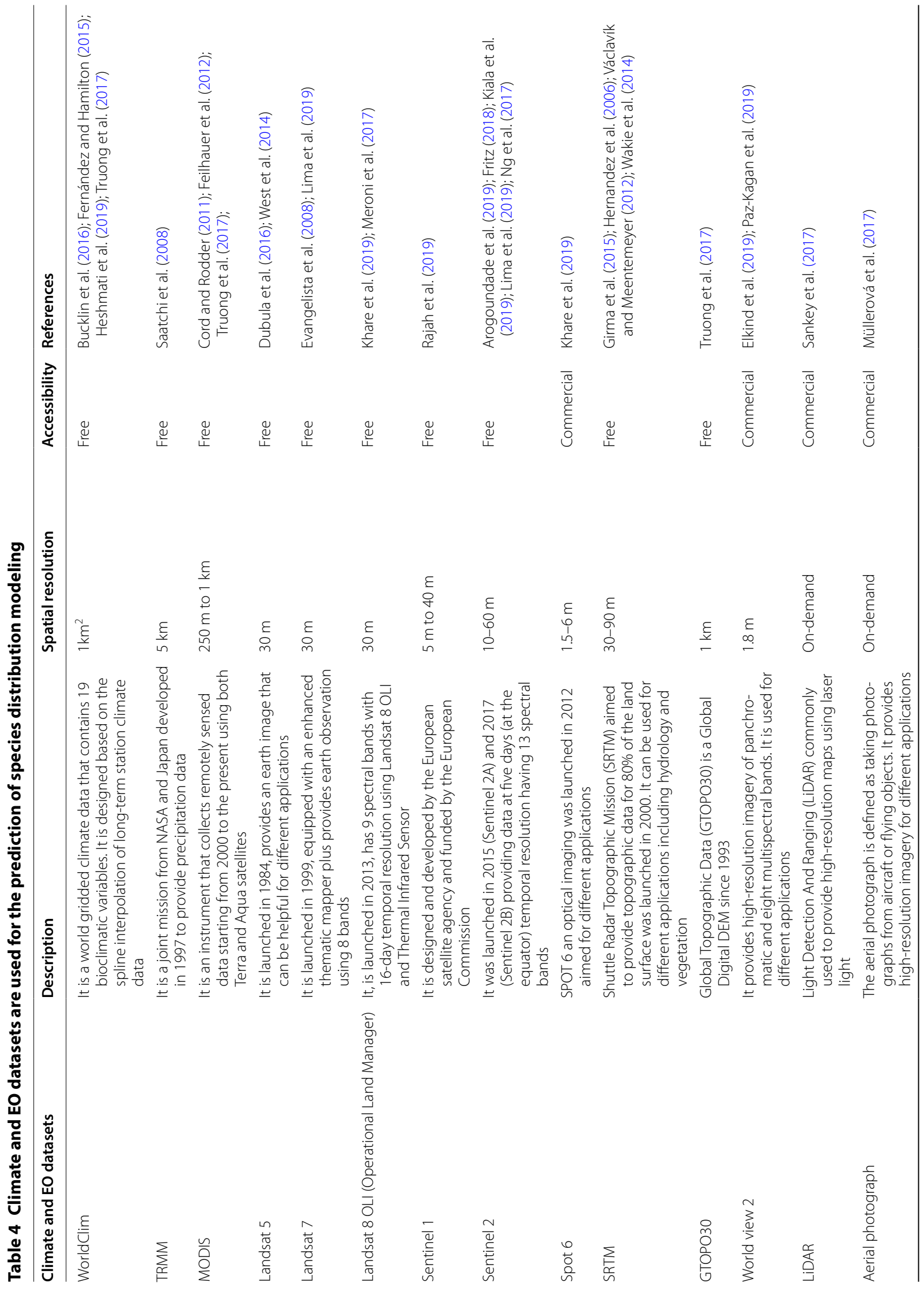




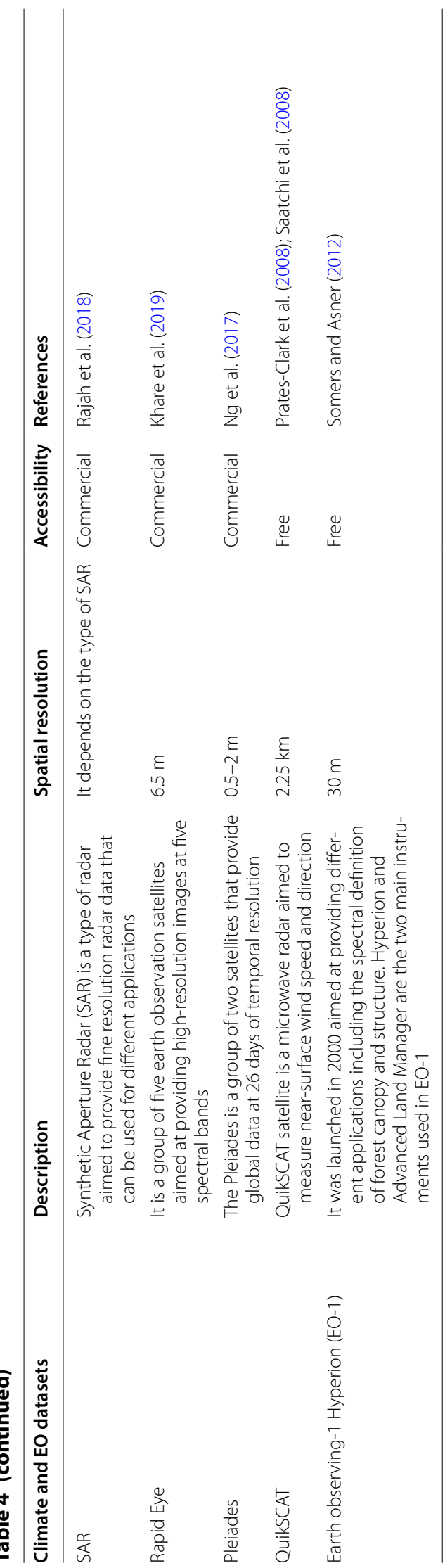


important advancement, as the integrating of different sensors will not only permit a better temporal and spatial resolution but will also leverage synergies from different band settings (Rajah et al. 2018). Furthermore, evaluating and boosting the capability of machine learning algorithms for the prediction of invasive species is necessary.

Bioclimatic variables derived from the WorldClim database are a good source of information for the prediction of invasive species. However, these records need to be updated using recent climate data as the latest version considers interpolation of climate data only from 1970 to 2000. Besides, there is also a need to integrate bioclimatic variables of WorldClim with remotely sensed bioclimatic variables to obtain a better spatial and temporal resolution. Moreover, evaluating the integration of remotely sensed environmental variables with bioclimatic variables in the prediction of invasive species is also necessary. Several studies (Truong et al. 2017; Cord et al. 2014a, b; Engler et al. 2013; Buermann et al. 2008) tried to evaluate the efficiency of bioclimatic and remote sensing variables separately and in combination. However, similar studies should be motivated for different species and geographic areas.

\section{Conclusion}

The integration of remote sensing and bioclimatic variables with SDM has the potential to play a key role in mapping and prediction of invasive species especially in arid and semi-arid areas where accessibility of environmental data is a challenge. Both datasets have their own advantages and hence it can be expected that the integration of both datasets provides richer and more predictive information. In data-poor regions where survey data is sparse, remote sensing can provide useful information due to its multi-temporal, spatial, and spectral resolution, and the resulting possibility to identify invasive species and to map certain environmental variables. On the other side, bioclimatic variables can solve some of the limitations of remotely sensed variables in relation to climate data. Hence, persistent information can possibly be obtained through the integration of both data sets. The integration of both datasets should in our opinion-and supported by the research community-be considered as a viable tool to increase the efficiency of SDM even though more research is required. It is also necessary to give due attention to presenting the guiding principle that helps to select variables and models for better accuracy of SDM. Furthermore, it is also necessary to validate remotely sensed (bio) climatic datasets and their integration with (spatially interpolated climate) data.

\section{Abbreviations}

SDM: Species Distribution Modelling; EO: Earth Observation; NDVI: Normalized Difference Vegetation Index; LAl: Leaf Area Index; EVI: Enhanced Vegetation Index; CRU: Climatic Research Unit; TRMM: Tropical Rainfall Measuring Mission; MODIS: Moderate Resolution Imaging Spectrometer; MSR: Modified Simple Ratio Index; RDVI: Renormalized Difference Vegetation Index; MCARI1: Modified Chlorophyll Absorption Ratio Index; GLM: Generalized Linear Model; RF: Random Forest; GAM: Generalized Additive Model; GBM: Gradient Boosted Model; SVM: Support Vector Machine; MARS: Multivariate Adaptive Regression Splines; UAV: Unmanned Aerial Vehicle; OLI: Operational Land Manager; SRTM: Shuttle Radar Topographic Mission; GTOP30: Global Topographic data; LiDAR: Light Detection and Ranging; SAR: Synthetic Aperture Radar.

\section{Acknowledgments}

This review paper is part of the doctoral study entitled "role of remote sensing in invasive species distribution modeling, the case of the lower Awash River basin, Ethiopia". We would like to thank Wollo University and the Ethiopian Space Science and Technology Institute (ESSTI) for allowing this doctoral study.

\section{Authors' contributions}

All authors made a valuable contribution. NA designed and wrote the methodology, collect literature, carried out data analysis, and wrote the draft manuscript; CA refines the methodology, support in collecting additional literature, rewrite the manuscript; and WZ supports in refining methodology, collection of additional literature, and refining the manuscript. All authors read and approved the final manuscript.

Funding

None.

Availability of data and materials

Not applicable.

Ethics approval and consent to participate

Not applicable.

\section{Consent for publication}

The authors agreed to submit the manuscript for publication in Environmental Systems Research. Besides we obtained permission from the publisher and author for Figs. 2 and 5 respectively.

\section{Competing interests}

The authors declare that there is no conflict of interest.

\section{Author details}

${ }^{1}$ Department of Remote Sensing, Ethiopian Space Science and Technology Institute (ESSTI), Entoto Observatory and Research Center, Addis Ababa, Ethiopia. ${ }^{2}$ Institute for Surveying, Remote Sensing and Land Information (IVFL), University of Natural Resources and Life Sciences, Vienna (BOKU), Peter JordanStraße 82, 1190 Vienna, Austria.

Received: 29 August 2020 Accepted: 26 October 2020 Published online: 10 November 2020

\footnotetext{
References

Ahmadi K, Alavi SJ, Amiri GZ, Hosseini SM, Serra-Diaz JM, Svenning J (2020) The potential impact of future climate on the distribution of European yew (Taxus baccata L.) in the Hyrcanian Forest region (Iran). Int J Biometeorol. https://doi.org/10.1007/s00484-020-01922-z

Amiri M, Tarkeshi M, Jafari R, Jetschke G (2020) Bioclimatic variables from precipitation and temperature records vs. remote sensing-based bioclimatic variables: which side can perform better in species distribution modeling. Ecol Inform 57(101060):1-16. https://doi.org/10.1016/j.ecoin f.2020.101060
} 
Aranda SC, Lobo JM (2011) How well does presence-only-based species distribution modeling predict assemblage diversity? a case study of the Tenerife flora. Ecography 34:31-38. https://doi.org/10.111 $1 / j .1600-0587.2010 .06134 . x$

Arogoundade AM, Odindi J, Mutanga O (2019) Modelling Parthenium hysterophorus invasion in KwaZulu-Natal province using remotely sensed data and environmental variables. Geocarto Int. https://doi. org/10.1080/10106049.2019.1581268

Asner GP, Knapp DE, Kennedy-bowdoin T, Jones MO, Martin RE, Boardman J, Hughes RF (2008) Invasive species detection in Hawaiian rainforests using airborne imaging spectroscopy and LiDAR. Remote Sens Environ 112:1942-1955. https://doi.org/10.1016/j.rse.2007.11.016

Ayanu Y, Jentsch A, Müller-Mahn D, Rettberg S, Romankiewicz C, Koellner T (2014) Ecosystem engineer unleashed: Prosopis juliflora threatening ecosystem services? Reg Environ Change 15(1):155-167. https://doi. org/10.1007/s10113-014-0616-x

Bartz R, Kowarik I (2019) Assessing the environmental impacts of invasive alien plants : a review of assessment approaches. NeoBiota 43:69-99. https:// doi.org/10.3897/neobiota.43.30122

Beaumont LJ, Hughes L, Poulsen M (2005) Predicting species distributions: use of climatic parameters in BIOCLIM and its impact on predictions of species' current and future distributions. Ecol Model 186:251-270. https ://doi.org/10.1016/j.ecolmodel.2005.01.030

Bekele K, Haji J, Legesse B, Schaffner U (2018) Economic impacts of Prosopis spp. invasions on dryland ecosystem services in Ethiopia and Kenya: evidence from choice experimental data. J Arid Environ. https://doi. org/10.1016/j.jaridenv.2018.07.001

Bellard C, Jeschke JM, Leroy B, Mace GM (2018) Insights from modeling studies on how climate change affects invasive alien species geography. Ecol Evol. https://doi.org/10.1002/ece3.4098

Beyene $\mathrm{H}$, Tessema T (2015) Distribution, abundance, and socio-economic impacts of parthenium (Parthenium hysterophorus). J Poverty Investment Dev 19:22-29

Boyd DS, Foody GM (2011) An overview of recent remote sensing and GISbased research in ecological informatics. Ecol Inform 6:25-36. https:// doi.org/10.1016/j.ecoinf.2010.07.007

Bradley BA (2014) Remote detection of invasive plants: a review of spectral, textural, and phenological approaches. Biol Invasions. https://doi. org/10.1007/s10530-013-0578-9

Bradley BA, Allen JM, O'Neill MW, Wallace RD, Bargeron CT, Richburg JA, Stinson K (2018) Invasive species risk assessments need more consistent spatial abundance data. Ecosphere 9(7):e02302. https://doi. org/10.1002/ecs2.2302

Bradley BA, Fleishman E (2008) Can remote sensing of land cover improve species distribution modeling? J Biogeogr 35:1158-1159. https://doi.org/1 0.1111/j.1365-2699.2008.01928.x

Bradley BA, Mustard JF (2006) Characterizing the landscape dynamics of an invasive plant and risk of invasion using remote sensing. Ecol Appl 16(3):1132-1147

Bucklin DN, Basille M, Romañach SS, Brandt LA, Mazzotti FJ, Watling J, Mazzotti F (2016) Considerations for building climate-based species distribution models. UF/IFAS extension University of Florida WE375: 1-8.

Buermann W, Saatchi S, Smith TB, Zutta BR, Chaves JA, Milá B, Graham CH (2008) Predicting species distributions across the Amazonian and Andean regions using remote sensing data. J Biogeogr. https://doi.org/ 10.1111/j.1365-2699.2007.01858.x

Cayuela L, Golicher DJ, Newton AC, Kolb M, de Alburquerque FS, Arets EJMM, Alkemade JRM, Pérez AM (2009) Species distribution modeling in the tropics: problems, potentialities, and the role of biological data for effective species conservation. Trop Conserv Sci 2(3):319-352

Cord AF, Klein D, Gernandt DS, de la Rosa JAP, Dech S (2014) Remote sensing data can improve predictions of species richness by stacked species distribution models: a case study for Mexican pines. J Biogeogr 41:736-748. https://doi.org/10.1111/jbi.12225

Cord AF, Klein D, Mora F, Dech S (2014) Comparing the suitability of classified land cover data and remote sensing variables for modeling distribution patterns of plants. Ecol Model 272:129-140. https://doi.org/10.1016/j. ecolmodel.2013.09.011

Cord AF, Meentemeyer RK, Leitao PJ, VaclaviKT (2013) Modelling species distributions with remote sensing data: bridging disciplinary perspectives. J Biogeogr 40:2226-2227. https://doi.org/10.1111/jbi.12199
Cord A, Rodder D (2011) Inclusion of habitat availability in species distribution models through multi-temporal remote-sensing data? Ecol Appl 21(8):3285-3298

Deblauwe V, Droissart V, Bose R, Sonké B, Blach-Overgaard A, Svenning J-C, Wieringa JJ, Ramesh BR, Stévart T, Couvreur TLP (2016) Remotely sensed temperature and precipitation data improve species distribution modeling in the tropics. Global Ecol Biogeogr 25:443-454. https://doi. org/10.1111/geb.12426

Diniz Filho JAF, Ferro VG, Santos T, Nabout JC, Dobrovolski R, De Marco JP (2010) The three phases of the ensemble forecasting of niche models: geographic range and shifts in climatically suitable areas of Utetheisa ornatrix. Revista Brasileira de Entomologia 54(3):339-349

Dubula B, Tesfamichael SG, Rampedi IT (2016) Assessing the potential of remote sensing to discriminate invasive Asparagus laricinus from adjacent land cover types. Cogent Geoscience 2:1154650. https://doi. org/10.1080/23312041.2016.1154650

Elkind K, Sankey TT, Munson SM, Aslan CE (2019) Invasive buffelgrass detection using high-resolution satellite and UAV imagery on Google Earth Engine. Remote Sens Ecol Conserv. https://doi.org/10.1002/rse2.116

Engler R, Waser LT, Zimmermann NE, Schaub M, Berdos S, Ginzler C, Psomas A (2013) Combining ensemble modeling and remote sensing for mapping individual tree species at high spatial resolution. For Ecol Manage 310:64-73. https://doi.org/10.1016/j.foreco.2013.07.059

Evangelista PH, Kumar S, Stohlgren TJ, Jarnevich CS, Crall AW, Norman JB, Barnett DT (2008) Modelling invasion for a habitat generalist and a specialist plant species. Diversity Distrib 14:808-817. https://doi.org/10. 1111/j.1472-4642.2008.00486.x

Feilhauer H, He KS, Rocchini D (2012) Modeling species distribution using niche-based proxies derived from composite bioclimatic variables and MODIS NDVI. Remote Sens 4:2057-2075. https://doi.org/10.3390/rs407 2057

Feilhauer H, Thonfeld F, Faude U, He KS, Rocchini D, Schmidtlein S (2013) Assessing floristic composition with multispectral sensors-a comparison based on monotemporal and multiseasonal field spectra. Int J Appl Earth Observ Geoinform 21:218-229. https://doi.org/10.1016/j. jag.2012.09.002

Fernández M, Hamilton H (2015) Ecological niche transferability using invasive species as a case study. PLoS ONE 10(3):e0119891. https://doi. org/10.1371/journal.pone.0119891

Fernandez M, Hamilton H, Kueppers L (2013) Characterizing uncertainty in species distribution models derived from interpolated weather station data. Ecosphere 4(5):61. https://doi.org/10.1890/ES13-00049

Fischer D, Thomas SM, Suk JE, Sudre B, Hess A, Tjaden NB, Beierkuhnlein C, Semenza JC (2013) Climate change effects on chikungunya transmission in Europe: Geospatial analysis of vector's climatic suitability and virus' temperature requirements. Int J Health Geographics 12(51):1-12. https://doi.org/10.1186/1476-072X-12-51

Fithian W, Elith J, Hastie T, Keith DA (2014) Special feature paper: bias correction in species distribution models: pooling survey and collection data for multiple species. Methods Ecol Evol. https://doi. org/10.1111/2041-210X.12242

Fritz A, Li L, Storch I, Koch B (2018) UAV-derived habitat predictors contribute strongly to understanding avian species-habitat relationships on the Eastern Qinghai-Tibetan Plateau. Remote Sens Ecol Conserv. https://doi. org/10.1002/rse2.73

Früh L, Kampen H, Kerkow A, Schaub GA, Walther D, Wieland R (2018) Modelling the potential distribution of an invasive mosquito species: comparative evaluation of four machine learning methods and their combinations. Ecol Model 388:136-144. https://doi.org/10.1016/j.ecolm odel.2018.08.011

Ge S, Everitt J, Carruthers R, Gong P, Anderson G (2006) Hyperspectral characteristics of canopy components and structure for phenological assessment. Environ Monit Assess 120:109-126. https://doi.org/10.1007/ s10661-005-9052-1

Girma A, de Bie CAJM, Skidmore AK, Venus V, Bongers F (2015) Hyper-temporal SPOT-NDVI dataset parameterization captures species distributions. Int J Geographical Inform Sci. https://doi.org/10.1080/13658 816.2015 .1082565

Godoy O, de Lemos-Filho JP, Valladares F (2011) Invasive species can handle higher leaf temperatures under water stress than Mediterranean 
natives. Environ Exp Bot 71:207-214. https://doi.org/10.1016/j.envex pbot.2010.12.001

Gormley AM, Forsyth DM, Griffioen P, Lindeman M, Ramsey DSL, Scroggie MP, Woodford L (2011) Using presence-only and presence-absence data to estimate the current and potential distributions of established invasive species. J Appl Ecol 48:25-34. https://doi.org/10.111 1/j.1365-2664.2010.01911.x

Guisan A, Zimmermann NE, Elith J, Graham CH, Phillips S, Peterson AT (2007) What matters for predicting the occurrences of trees: techniques, data, or species' characteristics? Ecol Monogr 77(4):615-630. https://doi. org/10.1890/06-1060.1

He KS, Bradley BA, Cord AF, Rocchini D, Tuanmu M, Schmidtlein S, Turner W, Wegmann M, Pettorelli N (2015) Will remote sensing shape the next generation of species distribution models? Remote Sens Ecol Conserv. https://doi.org/10.1002/rse2.7

Hernandez PA, Graham CH, Master LL, Albert DL (2006) The effect of sample size and species characteristics on performance of different species distribution modeling methods. Ecography 29:773-785

Heshmati I, Khorasani N, Shams-Esfandabad B, Riazi B (2019) Forthcoming risk of Prosopis juliflora global invasion triggered by climate change: implications for environmental monitoring and risk assessment. Environ Monit Assess 191(72):1-12. https://doi.org/10.1007/s10661-018-7154-9

Hijmans RJ, Cameron SE, Parra JL, Jones PG, Jarvis A (2005) Very high resolution interpolated climate surfaces for global land areas. Int J Climatol 25:1965-1978. https://doi.org/10.1002/joc.1276

Huang C-Y, Asner GP (2009) Applications of remote sensing to alien invasive plant studies. Sensors 9:4869-4889. https://doi.org/10.3390/s90604869

Hundessa N, Fufa A (2016) Distribution and socio-economic impacts of Prosopis juliflora in East Shewa and West Arsi Zones, Ethiopia. Int J African Asian Stud 24:31-41

Iluker J, Birner R, Tilahun M, Getu S (2014) A social-economic assessment of the impact of Prosopis juliflora invasion and participative management approach in the Afar Region, Ethiopia. Managing Prosopis Juliflora for Better (Agro-) Pastoral Livelihoods in the Horn of Africa 30-38.

Ilukor J, Rettberg S, Treydte A, Birner R (2016) To eradicate or not to eradicate? Recommendations on Prosopis juliflora management in Afar, Ethiopia, from an interdisciplinary perspective. Pastoralism Res Policy Pract 6(14):1-8. https://doi.org/10.1186/s13570-016-0061-1

Immitzer M, Neuwirth M, Böck S, Brenner H, Vuolo F, Atzberger C (2019) Optimal Input Features for tree species classification in Central Europe Based on Multi-Temporal Sentinel-2 Data. Remote Sens 11(2599):1-23. https://doi.org/10.3390/rs11222599

Jensen T, Hass FS, Akbar MS, Petersen PH, Arsanjani JJ (2020) Employing machine learning for detection of invasive species using Sentinel-2 and AVIRIS data: the case of Kudzu in the United States. Sustainability 12(3544):1-16. https://doi.org/10.3390/SU12093544

Jones CC (2012) Challenges in predicting the future distributions of invasive plant species. For Ecol Manage 284:69-77. https://doi.org/10.1016/j. foreco.2012.07.024

Kapitza K, Zimmermann H, Martín-lópez B, Von Wehrden H (2019) Research on the social perception of invasive species: a systematic literature review. NeoBiota 43:47-68. https://doi.org/10.3897/neobiota.43.31619

Khare S, Latifi H, Rossi S, Ghosh SK (2019) Fractional cover mapping of invasive plant species by combining very high-resolution stereo and multi-sensor multispectral imageries. Forests 10(540):1-15. https://doi. org/10.3390/f10070540

Kiala Z, Mutanga O, Odindi J, Peerbhay K (2019) Feature selection on sentinel-2 multispectral imagery for mapping a landscape infested by parthenium weed. Remote Sens 11(1892):1-17. https://doi.org/10.3390/rs11161892

Kissling WD, Ahumada JA, Bowser A, Fernandez M, Fern'andez N, García EA et al (2018) Building essential biodiversity variables (EBVs) of species distribution and abundance at a global scale. Biol Rev 93:600-625. https://doi.org/10.1111/brv.12359

Klerk H, Buchanan G (2017) Remote sensing training in African conservation. Remote Sens Ecol Conserv. https://doi.org/10.1002/rse2.36

Leitão PJ, Santos MJ (2019) Improving models of species ecological niches: a remote sensing overview. Ecol Evol Front. https://doi.org/10.3389/ fevo.2019.00009

Li G, Xu G, Guo K, Du S (2014) Mapping the global potential geographical distribution of black locust (Robinia Pseudoacacia L.) using herbarium data and a maximum entropy model. Forests 5:2773-2792. https:// doi.org/10.3390/f5112773

Lima TA, Beuchle R, Langner A, Grecchi RC, Griess VC, Achard F (2019) Comparing sentinel-2 MSI and landsat 8 OLI Imagery for monitoring selective logging in the Brazilian Amazon. Remote Sens 11(961):1-21. https://doi.org/10.3390/rs11080961

Loew A, Bell W, Brocca L, Bulgin CE, Burdanowitz J, Calbet X et al (2017) Validation practices for satellite-based Earth observation data across communities. Rev Geophys 55:779-817. https://doi. org/10.1002/2017RG000562

Matongera TN, Mutanga O, Dube T, Lottering RT (2016) Detection and mapping of bracken fern weeds using multispectral remotely sensed data: a review of progress and challenges. Geocarto Int. https://doi. org/10.1080/10106049.2016.1240719

Meroni M, Ng W-T, Rembold F, Leonardi U, Atzberger C, Gadain H, Shaiye M (2017) Mapping Prosopis juliflora in West Somaliland with Landsat 8 Satellite imagery and ground information. Land Degrad Dev 28:494-506. https://doi.org/10.1002/ldr.2611

Müllerová J, Bruna J, Bartalos T, Dvorak P, Vitkova M, Pyšek P (2017) Timing is important : unmanned aircraft vs. satellite imagery in plant invasion monitoring. Front Plant Sci. https://doi.org/10.3389/fpls.2017.00887

Ng W-T, Silva ACO, Rima P, Atzberger C, Immitzer M (2018) Ensemble approach for potential habitat mapping of invasive Prosopis spp. in Turkana Kenya. Ecol Evol 8(23):1-11. https://doi.org/10.1002/ ece3.4649

Ng W-T, Rima P, Einzmann K, Immitzer M, Atzberger C, Eckert S (2017) Assessing the potential of sentinel-2 and pléiades data for the detection of prosopis and vachellia spp. In Kenya. Remote Sens 9(74):1-29. https://doi.org/10.3390/rs9010074

Oumar Z (2016) Assessing the utility of the SPOT 6 sensor in detecting and mapping lantana camara for a community clearing project in KwaZulu-Natal, South Africa. South Afr J Geomatics 5(2):214-226. https://doi.org/10.4314/sajg.v5i2.9

Ouyang Z-T, Gao Y, Xie X, Guo H-Q, Zhang T-T, Zhao B (2013) Spectral discrimination of the invasive plant spartina alterniflora at multiple phenological stages in a saltmarsh wetland. PLoS ONE 8(6):e67315. https://doi.org/10.1371/journal.pone.0067315

Paz-Kagan T, Silver M, Panov N, Karnieli A (2019) Multispectral approach for identifying invasive plant species based on flowering phenology characteristics. Remote Sens 11(953):1-18. https://doi.org/10.3390/ rs11080953

Phillips SJ, Anderson RP, Schapire RE (2006) Maximum entropy modeling of species geographic distributions. Ecol Model 190:231-259. https:// doi.org/10.1016/j.ecolmodel.2005.03.026

Piiroinen R, Fassnacht FE, Heiskanen J, Maeda E, Mack B, Pellikka P (2018) Invasive tree species detection in the Eastern Arc Mountains biodiversity hotspot using one-class classification. Remote Sens Environ 218:119-131. https://doi.org/10.1016/j.rse.2018.09.018

Prates-Clark C, Saatchi SS, Agosti D (2008) Predicting geographical distribution models of high-value timber trees in the Amazon Basin using remotely sensed data. Ecol Model 211:309-323. https://doi. org/10.1016/j.ecolmodel.2007.09.024

Rajah P. Odindi J, Mutanga O (2018) Evaluating the potential of freely available multispectral remotely sensed imagery in mapping American bramble (Rubus cuneifolius). S Afr Geogr J. https://doi. org/10.1080/03736245.2018.1461683

Rajah P, Odindi J, Mutanga O, Kiala Z (2019) The utility of Sentinel-2 Vegetation Indices (VIS) and Sentinel-1 Synthetic Aperture Radar (SAR) for invasive alien species detection and mapping. Nat Conserv 35:41-61. https://doi.org/10.3897/natureconservation.35.29588

Re D, Tordoni E, De Pascalis F, Negri'n-Pe'rez Z, Ferna'ndez-Palacios J, Are'valo J, et al (2020) Invasive fountain grass (Pennisetum setaceum (Forssk) increases its potential area of distribution in Tenerife island under future climatic scenarios. Plant Ecol. https://doi.org/10.1007/ s11258-020-01046-9

Richter K, Atzberger C, Hank TB, Mauser W (2012) Derivation of biophysical variables from Earth observation data: validation and statistical measures. Appl Remote Sens 6:1-24. https://doi.org/10.1117/1. JRS.6.063557

Rocchini D, Boyd DS, Feret J-B, Foody GM, He KS, Lausch A, Nagendra H, Wegmann M, Pettorelli N (2015) Satellite remote sensing to monitor 
species diversity: potential and pitfalls. Remote Sens Ecol Conserv. https://doi.org/10.1002/rse2.9

Rocchini D, Andreo V, Forster M, Garzon-lopez CX, Gutierrez AP, Gillespie TW (2015) Potential of remote sensing to predict species invasions: a modeling perspective. Prog Phys Geogr 39(3):283-309. https://doi. org/10.1177/0309133315574659

Royimani L, Mutanga O, Odindi J, Dube T (2018) Advancements in satellite remote sensing for mapping and monitoring of alien invasive plant species (AIPs). Phys Chem Earth. https://doi.org/10.1016/j. pce.2018.12.004

Saatchi S, Buermann W, Steege H, Mori S, Smith TB (2008) Modeling distribution of Amazonian tree species and diversity using remote sensing measurements. Remote Sens Environ 112:2000-2017. https://doi. org/10.1016/j.rse.2008.01.008

Sakate DM, Kashid DN (2016) A new robust model selection method in GLM with application to ecological data. Environ Syst Res 5(9):1-8. https:// doi.org/10.1186/s40068-016-0060-7

Sankey TT, Mcvay J, Swetnam TL, Mcclaran MP, Heilman P, Nicholas M (2017) UAV hyperspectral and lidar data and their fusion for arid and semiarid land vegetation monitoring. Remote Sens Ecol Conserv. https:// doi.org/10.1002/rse2.44

Shackleton RT, Le Maitre DC, Van Wilgen BW, Richardson DM (2015) The impact of invasive alien Prosopis species (mesquite) on native plants in different environments in South Africa. South Afr J Botany 97:25-31. https://doi.org/10.1016/j.sajb.2014.12.008

Shackleton RT, Le Maitre DC, Pasiecznik NM, Richardson DM (2014) Prosopis: A global assessment of the biogeography, benefits, impacts and management of one of the world's worst woody invasive plant taxa. AoB PLANTS 6: plu027. https://doi.org/10.1093/aobpla/plu027

Shiferaw W, Demissew S, Bekele T (2018) Invasive alien plant species in Ethiopia: ecological impacts on biodiversity a review paper. Int J Mol Biol 3(4):169-176

Shiferaw H, Schaffner U, Bewket W, Alamirew T, Zeleke G, Teketay D, Eckert $S$ (2019a) Modelling the current fractional cover of an invasive alien plant and drivers of its invasion in a dryland ecosystem. Sci Rep 9(1576):1-12. https://doi.org/10.1038/s41598-018-36587-7

Shiferaw H, Bewket W, Alamirew T, Zeleke G, Teketay D, Bekele K, Schaffner U, Eckert S (2019b) Implications of land use/land cover dynamics and Prosopis invasion on ecosystem service values in Afar Region, Ethiopia. Sci Total Environ 675:354-366. https://doi.org/10.1016/j. scitotenv.2019.04.220

Shiferaw H, Bewket W, Eckert S (2019c) Performances of machine learning algorithms for mapping fractional cover of an invasive plant species in a dryland ecosystem. Ecol Evol. https://doi.org/10.1002/ece3.4919

Shoko C, Mutanga O (2017) Examining the strength of the newly-launched Sentinel 2 MSI sensor in detecting and discriminating subtle differences between C3 and C4 grass species. ISPRS J Photogrammetry Remote Sens 129:32-40. https://doi.org/10.1016/j.isprs jprs.2017.04.016

Singh K, Forbes A, Akombelwa M (2013) The Evaluation of high-resolution aerial imagery for monitoring of bracken fern. South Afr J Geomatics 2(4):296-308

Sintayehu DW, Dalle G, Bobasa AF (2020) Impacts of climate change on current and future invasion of Prosopis juliflora in Ethiopia: environmental and socio-economic implications. Heliyon 6:e04596. https://doi. org/10.1016/j.heliyon.2020.e04596

Somers B, Asner GP (2012) Hyperspectral time series analysis of native and invasive species in hawaiian rainforests. Remote Sens 4:2510-2529. https://doi.org/10.3390/rs4092510

Sun Y, Müller-schärer H, Maron JL, Schaffner U (2015) Origin matters : diversity affects the performance of alien invasive species but not of native species. Am Nat 185(6):725-736. https://doi. org/10.1086/681251

Taddese H (2014) Suitability analysis for Jatropha curcas production in Ethiopia-a spatial modeling approach. Environ Syst Res 3:25. https ://doi.org/10.1186/s40068-014-0025-7

Tamiru G (2017) Invasive alien weed species distribution, impacts on agriculture, challenge, and reaction in ethiopia: a review. J Biol Agric Healthcare 7(7):136-146
Thamaga KH, Dube T (2018a) Remote sensing of invasive water hyacinth (Eichhornia crassipes): a review on applications and challenges. Remote Sens Appl Soc Environ. https://doi.org/10.1016/j.rsase .2018 .02 .005

Thamaga KH, Dube T (2018b) Testing two methods for mapping water hyacinth (Eichhornia crassipes) in the Greater Letaba river system, South Africa: discrimination and mapping potential of the polar-orbiting Sentinel-2 MSI and Landsat 8 OLI sensors. Int J Remote Sens. https:// doi.org/10.1080/01431161.2018.1479796

Tola J, Tessema T (2019) Abundance and distribution of invasive alien plant species in Illu Ababora Zone abundance and distribution of invasive alien plant species in Illu Ababora Zone of Oromia National Regional State, Ethiopia. J Agric Sci Food Technol 1(7):94-100

Transon J, Andrimont R, Maugnard A, Defourny P (2018) Survey of hyperspectral earth observation applications from space in the sentinel-2 context. Remote Sens 10(157):1-32. https://doi.org/10.3390/rs 100 20157

Tricarico E (2016) Do alien invasive species and climate change foster conservation behavior? Aquatic Conserv: Mar. Freshw Ecosyst 26:228-232. https://doi.org/10.1002/aqc.2637

Truong TTA, Hardy G, Andrew ME (2017) Contemporary remotely sensed data products refine invasive plants risk mapping in datapoor regions. Front Plant Sci 8:1-18. https://doi.org/10.3389/ fpls.2017.00770

Tuanmu M-N, Jetz W (2014) A global 1-km consensus land-cover product for biodiversity and ecosystem modeling. Global Ecol Biogeogr 23(9):1-15. https://doi.org/10.1111/geb.12182

Urbina-Cardona N, Blair ME, London MC, Loyola R, Vela'squez-Tibata J, Morales-Devia H, (2019) Species distribution modeling in Latin America: a 25-year retrospective review. Trop Conserv Sci 12:1-19. https://doi.org/10.1177/1940082919854058

Václavík T, Meentemeyer K (2012) Equilibrium or not? Modelling the potential distribution of invasive species in different stages of invasion. Diversity Distrib 18:73-83

Vega GC, Pertierra LR, Olalla-tárraga MÁ (2017) Data descriptor: MERRAclim, a high-resolution global dataset of remotely sensed bioclimatic variables for ecological modeling. Sci Data. https://doi.org/10.1038/ sdata.2017.78

Vilà M, Espinar JL, Hejda M, Hulme PE, Jarošík V, Maron JL, Pergl J, Schaffner U, Sun Y, Pyšek P (2011) Ecological impacts of invasive alien plants: a meta-analysis of their effects on species, communities, and ecosystems. Ecol Lett 14:702-708. https://doi.org/10.111 $1 / j .1461-0248.2011 .01628 . x$

Vuolo F, Neuwirth M, Immitzer M, Atzberger C, Ng W-T (2018) How much does multi-temporal Sentinel-2 data improve crop type classification ? Int J Appl Earth Obs Geoinformation 72:122-130. https://doi. org/10.1016/j.jag.2018.06.007

Wakie TT, Evangelista PH, Jarnevich CS, Laituri M (2014) Mapping current and potential distribution of non-native Prosopis juliflora in the Afar region of Ethiopia. PLOS ONE 9(11):3-11. https://doi.org/10.1371/ journal.pone.0112854

Wakjira M (2011) An invasive alien weed giant sensitive plant (Mimosa diplotricha Sauvalle) invading Southwestern Ethiopia. Afr J Agric Res 6(1):127-131. https://doi.org/10.5897/AJAR10.421

Wessel M, Brandmeier M, Tiede D (2018) Evaluation of different machine learning algorithms for scalable classification of tree types and tree species based on sentinel-2 data. Remote Sens 10(1419):1-21. https ://doi.org/10.3390/rs10091419

West AM, Wakie T, Evangelista PH (2014). Mapping distribution and forecasting invasion of mesquite (Prosopis juliflora) in Ethiopia Ecological Forecasting Issue December): $1-18$

Wilson JW, Sexton JO, Todd Jobe R, Haddad NM (2013) The relative contribution of terrain, land cover, and vegetation structure indices to species distribution models. Biol Cons 164:170-176. https://doi. org/10.1016/j.biocon.2013.04.021

Xie Y, Sha Z, Yu M (2008) Remote sensing imagery in vegetation mapping : a review. J Plant Ecol 1(1):9-23. https://doi.org/10.1093/jpe/rtm005

Zhao M, Peng C, Xiang W, Deng X, Tian D, Zhou X, Yu G, He H, Zhao Z (2013) Plant phenological modeling and its application in global climate 
change research: overview and future challenges. Environ Rev 21:1-14. https://doi.org/10.1139/er-2012-0036

Zimmermann NE, Edwards TC Jr, Moisen GG, Frescino TS, Blackard JA (2007)

Remote sensing-based predictors improve distribution models of

rare, early successional and broadleaf tree species in Utah. J Appl

Ecol 44:1057-1067. https://doi.org/10.1111/j.1365-2664.2007.01348.x

\section{Publisher's Note}

Springer Nature remains neutral with regard to jurisdictional claims in published maps and institutional affiliations.

\section{Submit your manuscript to a SpringerOpen ${ }^{\odot}$ journal and benefit from:}

- Convenient online submission

- Rigorous peer review

- Open access: articles freely available online

- High visibility within the field

- Retaining the copyright to your article

Submit your next manuscript at $\boldsymbol{\nabla}$ springeropen.com 